\title{
Economic Impact of Grapevine Leafroll Disease on Vitis vinifera cv. Cabernet franc in Finger Lakes Vineyards of New York
}

\author{
Shady S. Atallah, ${ }^{1 *}$ Miguel I. Gómez, ${ }^{1}$ Marc F. Fuchs, ${ }^{2}$ \\ and Timothy E. Martinson ${ }^{3}$
}

\begin{abstract}
Leafroll disease is one of the most important virus diseases of grapevines worldwide. It reduces yields, delays fruit ripening, reduces soluble solids, and increases titratable acidity in fruit juice. This study uses a net present value (NPV) approach over a 25-year lifespan of a vineyard to examine the economic impact of grapevine leafroll disease (GLRD) on Vitis vinifera cv. Cabernet franc in Finger Lakes vineyards of New York. It identifies optimal disease control options under several scenarios of disease prevalence, yield reduction, and fruit quality effects. The estimated economic impact of GLRD ranges from approximately $\$ 25,000$ (for a $30 \%$ yield reduction and no grape quality penalty) to $\$ 40,000$ (for a $50 \%$ yield reduction and a $10 \%$ penalty for poor fruit quality) per hectare in the absence of any control measure. The per hectare impact of GLRD can be substantially reduced to $\$ 3,000-\$ 23,000$ through roguing if levels of disease prevalence are moderate $(1-25 \%)$. With disease prevalence levels greater than $25 \%$, replacing the entire vineyard is the optimal response, yielding economic losses of $\sim \$ 25,000$ / ha. Furthermore, the use of vines derived from certified, virus-tested stocks in replant sites is predicted to keep the costs associated with GLRD infection to $\sim \$ 1,800 /$ ha. No intervention appears to be economically optimal when (1) infection levels are high $(>25 \%)$, yield reduction is moderate $(<30 \%)$, and no price penalty is enforced or $(2)$ when GLRD is transmitted through vectors after year 19. These findings are valuable to construct integrated decision matrices for vineyard managers to devise profit-maximizing disease control strategies and to create incentives for extended uses of clean, virus-tested planting material.
\end{abstract}

Key words: grapevine leafroll disease (GLRD), Finger Lakes region New York, net present value, roguing, vine replacement

Grapevine leafroll disease (GLRD) is one of the most widespread viral diseases in vineyards. It is reported in almost all grape and wine regions in the United States (Fuchs et al. 2009a, Golino et al. 2008, Martin et al. 2005) and worldwide (Charles et al. 2009, Freeborough and Burger 2008, Martelli and Boudon-Padieu 2006). GLRD causes significant yield losses (up to $30-68 \%$ ), delays fruit ripening, reduces soluble solids, and increases titratable acidity in fruit juice (Goheen and Cook 1959, Martelli and Boudon-Padieu 2006, Martinson et al. 2008). Several phloem-limited filamentous

${ }^{1}$ Charles H. Dyson School of Applied Economics and Management, Cornell University, Ithaca, NY 14852, ${ }^{2}$ Department of Plant Pathology and Plant-Microbe Biology, and ${ }^{3}$ Department of Horticulture, New York State Agricultural Experiment Station, Cornell University, Geneva, NY 14456.

*Corresponding author (email: sa589@cornell.edu)

Acknowledgments: This research was supported by a grant from the U.S. Department of Agriculture, Viticultural Consortium, New York Wine and Grape Foundation and Lake Erie Regional Grape Program (grant 2009-34360-19879).

The authors thank the vineyard managers who participated in the survey and Gerald B. White whose initial work on the cost of production of $V$. vinifera in the Finger Lakes region of New York served as a basis for this study.

Supplemental data is freely available with the online version of this article at www.ajevonline.org.

Manuscript submitted Jun 2011, revised Sept 2011, accepted Oct 2011. Publication costs of this article defrayed in part by page fees.

Copyright $(\underset{2012}{ }$ by the American Society for Enology and Viticulture. All rights reserved.

doi: 10.5344/ajev.2011.11055 viruses, designated as grapevine leafroll-associated viruses (GLRaVs), were isolated and characterized from leafrollinfected grapevines (Ghanem-Sabanadzovic et al. 2010, Martelli and Boudon-Padieu 2006). All GLRaVs are readily transmitted via vegetative propagation and grafting, and some of them (GLRaV-1, GLRaV-3, GLRaV-5, and GLRaV-9) are also vectored by several species of mealybugs (Hemiptera: Pseudococcidae) and soft-scale insects (Hemiptera: Coccidae) (Martelli and Boudon-Padieu 2006, Tsai et al. 2010).

Vineyard managers adopt varied measures to manage GLRD (Martinson et al. 2008, Walker et al. 2004). Most tend to tolerate the disease without controlling it despite its evident detrimental impact on yield and fruit quality. In contrast, some managers replace infected vines with healthy ones (i.e., roguing), while a few opt for replanting entire vineyards. Disease control decisions rely on a variety of factors but often do not take into account the impact on maturity and berry color at harvest, likely because information about GLRD impact on profits is scarce. Therefore, vineyard managers may not make profit-maximizing decisions regarding GLRD control.

Little is known about the economic effects of GLRD, with a few notable examples. For instance, Walker et al. (2004) examined the impact of GLRaV-3 on gross margins in New Zealand vineyards using a model of virus spread under three infection scenarios (high, moderate, and low) over six growing seasons. These authors estimated damages of $\sim$ US $\$$ 21,200 /ha by years 12,15 , and 17 for the high, moderate, and 
low scenarios, respectively. Based on these results, the authors argued that replanting is justified in terms of increased profits by years 6,8 , and 11 for the same three scenarios, respectively. More recently, a net present value (NPV) approach was used to measure the economic costs of GLRaV-3 for $V$. vinifera cv. Sauvignon blanc and Merlot in New Zealand (Nimmo-Bell 2006). The study compared the per hectare NPV of infected and virus-free vineyard blocks under three scenarios of disease control: total vine removal in year 6 , annual roguing of infected vines, and annual roguing of infected and neighboring vines. The authors concluded that early vine roguing is more cost-effective than total vineyard replacement in year 6 . Vine roguing reduced the disease impact six-fold for Sauvignon blanc and seven-fold for Merlot when compared to a "no intervention" scenario. In a study on the economic impact of GLRaV-3 on a $V$. vinifera Cabernet Sauvignon vineyard in the Stellenbosch region of South Africa, roguing was identified as the only viable alternative to increase profits (Freeborough and Burger 2008).

In this study, we estimated the profitability impact of GLRD in grafted $V$. vinifera cv. Cabernet franc in Finger Lakes vineyards of New York. These estimates, in turn, were used to recommend loss-minimizing management strategies for disease control. Specifically, the NPV approach was used to compare several GLRD control strategies, including roguing, replacing the entire vineyard, and no action. These management strategies were used to quantify disease damage under several scenarios and to identify optimal management strategies based on infection level, extent of yield reduction, penalties imposed on fruit quality, and vineyard age.

\section{Materials and Methods}

Survey of vineyard managers. To construct economic analysis scenarios, a survey was conducted among 10 vertically integrated vineyard-winery operations in the Finger Lakes region of New York State from fall 2009 through spring 2010. The wineries selected had vineyards with a history of GLRD infection based on grafted $V$. vinifera cultivars, including cv. Cabernet franc, showing typical leafroll symptoms or GLRaV-1, GLRaV-2, and/or GLRaV-3 infection as indicated by ELISA and/or RT-PCR (Fuchs et al. 2009b). Respondents provided information about perceived ranges of GLRD prevalence, magnitudes of yield reduction due to the disease, disease control measures adopted by vineyard managers, and penalties incurred due to poor fruit quality (see survey instrument in Supplemental Data). For completeness, the survey included data on all cultivars affected by GLRD. However, the analysis focused on Cabernet franc for two reasons. First, GLRD symptoms are more visible in red than in white grape varieties (Martelli and Boudon-Padieu 2006) and roguing is therefore more easily implemented. Second, GLRD affects Cabernet franc more than other cultivars because it ripens later. This feature is crucial for cool-climate viticultural regions such as the Finger Lakes because the short growing season and early frost preclude delaying harvest to compensate for delayed ripening in GLRD-affected vines, which may be an option in areas with a longer growing season. The survey responses were used to specify the parameter ranges for constructing the analysis scenarios.

Parameters for disease management scenarios. $G L R D$ prevalence. Vineyard managers reported approximately 1, 5, and $40 \%$ levels of GLRD infection. These values, as well as other prevalence values retrieved from the literature, were considered to identify threshold levels that determine switching from one management option to another. Vineyard managers recognized that the occurrence of GLRD was mainly through infected vines at the time of planting.

Spread of GLRD by vectors. Managers did not recognize a pattern of virus spread via mealybug and soft-scale insects, despite the documented presence of vectors species, including viruliferous individuals, in local vineyards (Fuchs et al. 2009 b). The analysis used a model of GLRaV-3 spread described elsewhere (Charles et al. 2009) to predict levels of virus infection in the presence of vectors. In that model, a GLRD prevalence of $50 \%$ was predicted in years 6,8 , and 11 for the three vineyards studied with low, medium, and high GLRD infection risk, respectively, and $90 \%$ in years 11,12 , and 15 (Charles et al. 2009). The data on GLRD spread over time in the medium infection risk case was used to construct this study's scenario of "no GLRD control" (Table 1, column N).

Methods of GLRD control. Vineyard managers practiced roguing (identifying, removing, and replacing infected vines with vines derived from certified, virus-tested vines), replaced entire vineyards with virus-tested certified vines, or did not respond to GLRD.

\begin{tabular}{|c|c|c|c|c|c|c|c|c|}
\hline \multirow[b]{2}{*}{ Years } & \multicolumn{5}{|c|}{ Vines infected (\%) } & \multicolumn{3}{|c|}{ Yield (t/ha) } \\
\hline & $\mathrm{N}^{\mathrm{a}}$ & $\mathrm{T} 1^{\mathrm{b}}$ & T5 & T40 & T60 & Healthy & $\begin{array}{c}50 \% \\
\text { reduction }\end{array}$ & $\begin{array}{c}30 \% \\
\text { reductionc }\end{array}$ \\
\hline 0 & 0 & $-d$ & - & - & - & 0 & 0 & 0 \\
\hline 1 & 1 & - & - & - & - & 0 & 0 & 0 \\
\hline 2 & 2 & - & - & - & - & 0 & 0 & 0 \\
\hline 3 & 8 & - & - & - & - & 2.2 & 2.15 & 2.17 \\
\hline 4 & 12 & 1 & 5 & 40 & 60 & 7.4 & 6.94 & 7.12 \\
\hline 5 & 22 & 1 & 3 & 20 & 40 & 7.4 & 6.58 & 6.89 \\
\hline 6 & 28 & 1 & 1 & 10 & 20 & 7.4 & 6.36 & 6.76 \\
\hline 7 & 36 & 1 & 1 & 5 & 10 & 7.4 & 6.07 & 6.58 \\
\hline 8 & 48 & 1 & 1 & 3 & 5 & 7.4 & 5.62 & 6.31 \\
\hline 9 & 60 & 1 & 1 & 1 & 3 & 7.4 & 5.17 & 6.07 \\
\hline 10 & 70 & 1 & 1 & 1 & 1 & 7.4 & 4.81 & 5.84 \\
\hline 11 & 80 & 1 & 1 & 1 & 1 & 7.4 & 4.43 & 5.62 \\
\hline 12 & 88 & 1 & 1 & 1 & 1 & 7.4 & 4.14 & 5.44 \\
\hline 13 & 92 & 1 & 1 & 1 & 1 & 7.4 & 3.98 & 5.35 \\
\hline 14 & 95 & 1 & 1 & 1 & 1 & 7.4 & 3.87 & 5.28 \\
\hline $15-19$ & 98 & 1 & 1 & 1 & 1 & 7.4 & 3.76 & 5.21 \\
\hline $20-25$ & 100 & 1 & 1 & 1 & 1 & 7.4 & 3.69 & 5.17 \\
\hline
\end{tabular}

aN: GLRD infection levels derived from the model of Walker et al. (2004) for the no control scenario.

${ }^{\mathrm{b}} \mathrm{T} 1, \mathrm{~T} 5, \mathrm{~T} 40$, and T60: roguing scenarios at 1, 5, 40, and $60 \%$ initial infection levels. GLRD prevalence under roguing was assumed to decrease following a stepwise pattern.

"Yield was calculated as \%infected vines*yield of infected vines + $\%$ healthy vines*yield of healthy vines where yield reduction due to GLRD is assumed to be $50 \%$ and $30 \%$.

dlt is assumed that GLRD is due to rootstock infection; therefore, 0- to 3-yr-old vines do not develop GLRD symptoms. 
Yield reduction due to GLRD infection. For the most part, vineyard managers did not attempt to measure yield reduction due to GLRD. Therefore, the literature was reviewed and yield reductions of $30 \%$ and $50 \%$ were considered, given that losses of 30 to $68 \%$ are commonly reported (Goheen and Cook 1959, Martelli and Boudon-Padieu 2006, Martinson et al. 2008, Over de Linden and Chamberlain 1970).

Alteration of fruit quality due to GLRD infection. The survey quantified quality reduction due to increases in titratable acidity and reductions in sugar content of fruit juice at harvest. It also identified contractual mechanisms used by buyers to penalize poor quality grapes. Vineyard managers did not systematically measure the impact of GLRD on fruit juice chemistry. Instead, buyers inspected fruits and measured acidity and sugar levels. No vineyard manager reported rejection due to low quality grapes, but one winery imposed a $10 \%$ price penalty when buying grapes that did not meet a sugar level requirement ranging from 15 to 21 Brix depending on the cultivar. For that reason, two additional scenarios were added (NN30 and NN50) to identify any effect of the penalty incentive on the vineyard managers' management decisions.

Integration of survey data. The answers provided by vineyard managers were used to identify parameter values to be considered in the analysis. These parameter values were combined to create scenarios under which the economic impact of GLRD was estimated (Table 2). Given that the study focused on Cabernet franc, data collected on GLRD incidence on other cultivars (section 2 of survey instrument in Supplemental Data) were not included in the analysis.

Scenarios to assess GLRD impact. Various scenarios were constructed, reflecting the cash flow of one hectare of $V$. vinifera $\mathrm{cv}$. Cabernet franc over 25 years (the typical lifespan of a vineyard in the Finger Lakes). These scenarios differ by the biological and managerial parameters reported in the survey. Biological parameters include mode of disease transmission (through infected vines at time of planting for several levels of initial infection or, later on, through insect vectors) and various levels of yield impact (30 or 50\% yield reduction). Management parameters, for their part, include disease control measures (no control, roguing at infection levels ranging from 1 to $60 \%$, or entire vineyard replacement), and impact of the disease on price paid for the grapes because of quality losses (10\% penalty or no penalty). Additional scenarios were considered to analyze how vineyard age might impact GLRD control decisions (ages 12, 16, and 20) and to assess the value of disease prevention by planting vines procured from certified, virus-tested stocks. The following scenarios were considered (Table 2), based on the survey responses from vineyard managers.

Scenario 1: Baseline (B). The baseline scenario consisted of a cash flow for one vineyard hectare over 25 years with no GLRD prevalence. The baseline scenario was used as a benchmark to estimate the economic impact of GLRD under the scenarios described below. To this effect, the GLRD impact was computed as the difference between the baseline NPV and the NPV of each alternative scenario.

Scenario 2: No disease control (N). In this scenario GLRD was introduced in year 1 (either through insect vectors or at planting through infected vines at a level of $1 \%$ ), spread following the logistic model suggested by Charles et al. (2009), and the vineyard manager decided not to rogue or replace the vineyard. Disease spread is summarized in Table 1 where column $\mathrm{N}$ lists the percentages of vines infected over time. Scenario 2 was analyzed with a yield reduction of 30 and $50 \%$, under either no penalty (NN30 and NN50) or a 10\% penalty rate (N30 and N50) due to lower quality grapes. This yielded four scenarios that were used to estimate the economic impact of GLRD when no control measures are implemented.

Scenario 3: GLRD prevention through establishing vineyards with planting material derived from certified, virustested stocks $(C)$. This scenario simulated a situation where the vines used in a planting or replant site were derived from certified, virus-free stocks and cost $25 \%$ more than conventional vines, based on market prices. The NPV of this scenario

\begin{tabular}{|c|c|c|c|c|c|c|c|c|c|}
\hline \multirow[b]{2}{*}{ Scenario } & \multirow{2}{*}{$\begin{array}{c}\text { Initial } \\
\text { infection (\%) }\end{array}$} & \multicolumn{3}{|c|}{ Yield reduction (\%) } & \multicolumn{2}{|c|}{ Quality penalty (\%) } & \multicolumn{3}{|c|}{ GLRD introduction $^{\mathrm{a}}$} \\
\hline & & 0 & 30 & 50 & 0 & 10 & None & Vines & Vectors \\
\hline Baseline (B) & 0 & $x$ & & & $x$ & & $x$ & & \\
\hline \multicolumn{10}{|l|}{ No disease control $(\mathrm{N})^{\mathrm{b}}$} \\
\hline NN50 & 1 & & & $x$ & $x$ & & & $x$ & $x$ \\
\hline NN30 & 1 & & $\mathrm{x}$ & & $\mathrm{x}$ & & & $\mathrm{x}$ & $x$ \\
\hline N50 & 1 & & & $x$ & & $x$ & & $x$ & $x$ \\
\hline N30 & 1 & & $x$ & & & $x$ & & $x$ & $x$ \\
\hline Planting certified, virus-tested vines (C) & 0 & $x$ & & & $x$ & & $x$ & & \\
\hline Roguing (T1-T60) & $1-60$ & $x$ & & & $x$ & & & $x$ & \\
\hline Replacement (R) & any & $\mathrm{na}^{\mathrm{c}}$ & na & na & na & na & & $x$ & $x$ \\
\hline $\begin{array}{l}\text { No disease control, late vector-mediated } \\
\text { infection (NLV) }\end{array}$ & 0 & & & $\mathrm{x}$ & & $\mathrm{x}$ & & & $\mathrm{x}$ \\
\hline Roguing, late vector-mediated infection (TLV) & 0 & $x$ & & & $x$ & & & & $x$ \\
\hline
\end{tabular}

${ }^{a}$ GLRD transmission within vineyards not included as it is assumed to be vector-mediated in all scenarios.

${ }^{b} N$ 50: no control, no penalty, 50\% yield reduction; NN30: no control, no penalty, 30\% yield reduction; N50: no control, $10 \%$ penalty, $50 \%$ yield reduction; and N30: no control, $10 \%$ penalty, $30 \%$ yield reduction.

cna: not applicable. 
was used to examine the benefits of a preventative approach to GLRD by procuring clean vines at the time of planting in situations where vines of poor sanitary status are the only source of infection.

Scenario 4: Roguing scenarios (T1-T60). These scenarios correspond to situations where GLRD was introduced at planting at different levels ranging from 1 to $60 \%$ (T1 to T60) via diseased rootstocks and/or scion. Infected vines started developing GLRD symptoms in year 4 and were subsequently rogued as they became symptomatic. Asymptomatic, infected vines were not identified nor removed and the disease could be reintroduced through insect vectors. Therefore, disease prevalence does not drop immediately but rather decreases in a stepwise pattern, as initially asymptomatic vines develop symptoms over time and are rogued. It is assumed that the disease is never eradicated and is controlled at $1 \%$ at best. The stepwise decrease in disease prevalence was formulated for roguing scenarios with varied initial infection levels (T1, T5, T40, and T60) (Table 1). These parameters were used to identify the threshold infection level below which roguing is advisable and above which vineyard replacement is the appropriate response. In the roguing scenarios, it is assumed that there are no GLRD-led reductions in yield or quality.

Scenario 5: Vineyard replacement (R). In this scenario, the vineyard manager decided to replant the entire vineyard at the onset of symptoms in year 4. This scenario reflects actions of surveyed managers who are willing to invest in replanting to avoid the uncertainty of coping with GLRD and to minimize the probability of within-vineyard disease spread. The NPV of this scenario was used as a benchmark to identify infection level ranges that warrant vineyard replacement instead of roguing.

Scenario 6: Late vector-mediated GLRD infection (LVM). Here GLRD was introduced through insect vectors in years 12,16 , or 20 with (TLV) or without (NLV) roguing. It identifies a possible vineyard age beyond which no intervention would be recommended given a vineyard lifespan of 25 years.

Economic analysis. A NPV per hectare was calculated for each GLRD control scenario over the economic lifetime of vineyards (25 years). GLRD impacts were computed as the difference between the baseline NPV (i.e., no infection) and the NPV of the particular scenario considered. The NPV calculations are based on data (costs, revenues, and financial assumptions) reported previously (White 2008) (Table 3), on survey data collected (disease prevalence, impact on yield, and price paid for the grapes), and on findings from the literature. Fixed costs were omitted from the analysis because they are identical for the different scenarios. Optimal control measures were identified as those with the highest NPV.

\section{Results}

Economic impact of GLRD. The economic impact of GLRD over the lifetime of a Cabernet franc vineyard in the Finger Lakes ranges from $\$ 25,407 /$ ha (for a $30 \%$ yield reduction and no quality penalty) to $\$ 41,000 /$ ha (for a $50 \%$ yield reduction and a $10 \%$ penalty for poor fruit quality) if no control measures are implemented (Table 4).
Value of planting vines derived from certified, virus-tested stocks. Results indicate that paying a price premium of $25 \%$ for clean plant material (i.e., $25 \%$ in addition to the noncertified vine price of $\$ 3.25 /$ vine; Table 3) reduces GLRD-related losses to $\$ 1,829 /$ ha. This loss is substantially less than those following roguing and vineyard replacement (Table 5). This estimate does not take into account the possibility of a subsequent introduction of GLRD through vectors; rather, it focuses on the value of using certified vines to prevent the introduction of GLRD at planting.

Roguing or vineyard replacement. The NPVs for roguing at various levels of initial infection and vineyard replacement suggest a threshold level of disease prevalence beyond which the optimal GLRD control is to replace the vineyard (Table 5, Table 6). Roguing yields higher NPVs than vineyard replacement for prevalence levels of $25 \%$ and below; vineyard replacement yields the highest NPV for prevalence levels above $25 \%$. The infection threshold is consistent with the survey responses. For example, a respondent that reported a $40 \%$

Table 3 Cabernet franc production, cost, revenue, and financial assumptions.

\begin{tabular}{lll}
\hline & \multicolumn{1}{c}{ Variable } & $\begin{array}{l}\text { Values } \\
\text { and units }\end{array}$ \\
\hline Production & Row spacing & $2.7 \mathrm{~m}$ \\
& Vine spacing & $1.8 \mathrm{~m}$ \\
& Planting density & $1,994 \mathrm{vines} / \mathrm{ha}$ \\
Cost & Vine replacement without GLRD & $2 \%$ \\
& Skilled labor wage & $\$ 16.6 / \mathrm{hr}$ \\
& Unskilled labor wage & $\$ 11.60 / \mathrm{hr}$ \\
& Gasoline & $\$ 0.76 / \mathrm{L}$ \\
Revenue & Diesel & $\$ 0.87 / \mathrm{L}$ \\
& Vines & $\$ 3.25 / \mathrm{vine}$ \\
Financial & Price & $\$ 1,874 / \mathrm{t}$ \\
& Yield (years 4 and above) & $7.4 \mathrm{t} / \mathrm{ha}$ \\
& Discount rate & $7.37 \%$ \\
& Project life cycle & $25 \mathrm{years}$ \\
\hline
\end{tabular}

Source: White (2008).

Table 4 Net present value (NPV) of no GLRD control scenarios under different Cabernet franc yield reduction (30 and 50\%) and quality penalty (0 and $10 \%)$ conditions.

\begin{tabular}{lcc}
\hline Scenario & $\begin{array}{c}\text { NPVb } \\
(\$ / h a)\end{array}$ & $\begin{array}{c}\text { GLRD } \\
\text { economic impact } \\
(\$ / h a)\end{array}$ \\
\hline $\begin{array}{l}\text { No control, no penalty, } \\
\text { 30\% yield reduction (NN30) }\end{array}$ & $\$ 7,690$ & $\$ 25,407$ \\
$\begin{array}{l}\text { No control, 10\% penalty, } \\
\text { 30\% yield reduction (N30) }\end{array}$ & $\$ 6,786$ & $\$ 26,334$ \\
$\begin{array}{l}\text { No control, no penalty, } \\
50 \% \text { yield reduction (NN50) }\end{array}$ & $(\$ 7,119)$ & $\$ 40,241$ \\
$\begin{array}{l}\text { No control, 10\% penalty, } \\
50 \% \text { yield reduction (N50) }\end{array}$ & $(\$ 7,900)$ & $\$ 41,019$ \\
Replacement (R) & $\$ 8,468$ & $\$ 24,651$ \\
\hline
\end{tabular}

aSee description of scenarios in Table 1.

${ }^{b}$ Numbers in parenthesis represent losses.

'Computed as the difference between the NPV of roguing and the baseline NPV.

${ }^{\mathrm{d} R e p l a c e m e n t: ~ r e p l a c i n g ~ v i n e y a r d ~ a t ~ o n s e t ~ o f ~ s y m p t o m s ~ i n ~ y e a r ~} 4$. 
GLRD prevalence decided to replace the vineyard, whereas others dealing with infection levels of 1 and $5 \%$ practiced roguing. Under optimal GLRD control, the disease impact is reduced to a range of $\$ 3,208$ to $\$ 24,654 /$ ha for scenarios of roguing at $1 \%$ GLRD prevalence and vineyard replacement, respectively (Table 5).

Late vector-mediated GLRD infection. Roguing has a positive impact on NPV even when infection occurs at a later stage and reduces losses by $\$ 9,271$ and $\$ 11,733 /$ ha in years 12 and 16, respectively (Table 7). However, roguing increases losses in year 19 and after, suggesting a threshold vineyard age beyond which roguing is not optimal. This threshold places an upper limit on the age of the vineyard under which roguing remains economical: investing in planting new vines five years before the end of the lifecycle is not justified.

Table 5 Economic impact of GLRD in a Cabernet franc vineyard under planting virus-tested vines, vine roguing, and vineyard replacement.

\begin{tabular}{lcc}
\hline Scenario $^{\mathrm{a}}$ & $\begin{array}{c}\text { NPVb } \\
\mathbf{( \$ / h a )}\end{array}$ & $\begin{array}{c}\text { GLRD impact } \\
\text { (\$/ha) }\end{array}$ \\
\hline Baseline (B) & $\$ 33,122$ & $\$ 0$ \\
Establishing vineyard with & $\$ 31,291$ & $\$ 1,829$ \\
certified, virus-tested vines (C) & & \\
Roguing (T1-T60) & & \\
1 & $\$ 29,915$ & $\$ 3,207$ \\
5 & $\$ 26,084$ & $\$ 7,038$ \\
10 & $\$ 22,351$ & $\$ 10,771$ \\
20 & $\$ 14,275$ & $\$ 18,847$ \\
25 & $\$ 9,815$ & $\$ 23,307$ \\
26 & $\$ 8,115$ & $\$ 25,007$ \\
30 & $\$ 5,261$ & $\$ 27,861$ \\
40 & $\$ 2,000$ & $\$ 35,121$ \\
50 & $(\$ 9,244)$ & $\$ 42,366$ \\
60 & $\$ 22,914)$ & $\$ 56,036$ \\
Replacement (R) & $\$ 8,468$ & $\$ 24,654$ \\
\hline
\end{tabular}

aT1 to T60: roguing scenarios at $1 \%$ to $60 \%$ initial infection levels, respectively. R: replacing vineyard at onset of symptoms in year 4.

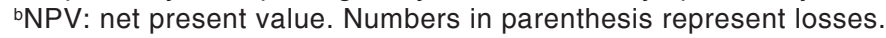
${ }^{\mathrm{c} C o m p u t e d}$ as the difference between the NPV of roguing and the baseline NPV.

Table 6 GLRD control decision matrix in a Cabernet franc vineyard based on yield reduction, GLRD prevalence, and a quality penalty.

\begin{tabular}{|c|c|c|}
\hline \multirow[b]{2}{*}{ Yield reduction } & \multicolumn{2}{|c|}{ Penalty level } \\
\hline & $10 \%$ & None \\
\hline \multicolumn{3}{|l|}{$30 \%$ reduction } \\
\hline$\leq 25 \%$ infection & rogue $^{a}$ & rogue \\
\hline$>25 \%$ infection & replace vineyard & indifferent \\
\hline \multicolumn{3}{|l|}{$<30 \%$ reduction } \\
\hline$\leq 25 \%$ infection & rogue & rogue \\
\hline$>25 \%$ infection & replace vineyard & do not control \\
\hline \multicolumn{3}{|l|}{$50 \%$ reduction } \\
\hline$\leq 25 \%$ infection & rogue & rogue \\
\hline$>25 \%$ infection & replace vineyard & replace vineyard \\
\hline
\end{tabular}

${ }^{a}$ Recommendations in decision matrix are based on results from Tables 4 and 5.
No control. Roguing is optimal for disease management with a $50 \%$ yield reduction because the "no control" scenario yields negative NPVs (Table 4, rows NN50 and N50). However, no control was economically optimal in certain instances. For example, for a $30 \%$ yield reduction and no penalty for poor fruit quality, the NPV (Table 4, row NN30) equals the NPV of vineyard replacement (Table 5). This result suggests that no control is the optimal response when the level of infection is greater than $25 \%$ (i.e., for the range where vineyard replacement is optimal), yield reduction is less than $30 \%$, and there is no quality penalty. The optimality of no control in this case ignores the potential negative effects caused by disease transmission to neighboring vineyards through insect vectors. If that occurs, replacing vineyard blocks with infection levels greater than $25 \%$ may be advisable.

Changes in grape prices below and above the baseline price of $\$ 1,700 / t$ did not lead to changes in the recommendation of roguing when GLRD prevalence is $25 \%$ and below and replacing the vineyard otherwise (Table 8).

\section{Discussion}

The economic impact of GLRD on grafted $V$. vinifera $\mathrm{cv}$. Cabernet franc in New York $(\sim 25,000-40,000 / \mathrm{ha})$ is consistent with losses reported by Walker et al. (2004) ( $\sim \$ 33,000$ $\$ 50,000 /$ ha by year 20 for three scenarios of infection risk)

\begin{tabular}{|c|c|c|}
\hline LVM infection scenario & $\begin{array}{l}\text { NPVa } \\
\text { (\$/ha) }\end{array}$ & $\underset{(\$ / h a)}{\text { Roguing impact }}$ \\
\hline Year 12, no roguing (NLV12) & $\$ 23,502$ & \\
\hline Year 12, roguing (TLV12) & $\$ 32,774$ & $\$ 9,272$ \\
\hline Year 16, no roguing (NLV16) & $\$ 18,286$ & \\
\hline Year 16, roguing (TLV16) & $\$ 30,018$ & $\$ 11,733$ \\
\hline Year 20, no roguing (NLV20) & $\$ 31,118$ & \\
\hline Year 20, roguing (TLV20) & $\$ 30,270$ & $(\$ 848)$ \\
\hline
\end{tabular}

aNPV computed using infection levels from Table 2 , column $\mathrm{N}$. ${ }^{b}$ Roguing impact computed as the difference between the NPV of roguing and the NPV of no roguing. Numbers in parenthesis represent losses.

Table 8 Sensitivity analysis with respect to the price $(p)$ of Cabernet franc grapes: the recommendation of replacing the vineyard beyond $25 \%$ GLRD prevalence is unchanged.

\begin{tabular}{|c|c|c|c|}
\hline \multirow[b]{2}{*}{ Disease control } & \multicolumn{3}{|c|}{ NPV (\$/ha) } \\
\hline & $p=\$ 1,764 / t$ & $p=\$ 1874 / t$ & $\mathrm{p}=\$ 1984.5 / \mathrm{t}$ \\
\hline $\begin{array}{l}\text { Roguing at } 20 \% \text { GLRD } \\
\text { (T20) }\end{array}$ & $\$ 7,816$ & $\$ 14,275$ & $\$ 20,732$ \\
\hline $\begin{array}{l}\text { Roguing at } 25 \% \text { GLRD } \\
\text { (T25) }\end{array}$ & $\$ 3,506$ & $\$ 9,815$ & $\$ 16,124$ \\
\hline $\begin{array}{l}\text { Roguing at } 26 \% \text { GLRD } \\
\text { (T26) }\end{array}$ & $\$ 1,307$ & $\$ 8,115$ & $\$ 13,779$ \\
\hline $\begin{array}{l}\text { Roguing at } 30 \% \text { GLRD } \\
\text { (T30) }\end{array}$ & $(\$ 813)^{a}$ & $\$ 5,261$ & $\$ 11,332$ \\
\hline Replacement (R) & $\$ 2,439$ & $\$ 8,468$ & $\$ 14,498$ \\
\hline
\end{tabular}

aNumbers in parenthesis represent losses. 
and Nimmo-Bell (2006) ( $\$ 47,000 /$ ha) on $V$. vinifera cvs. Sauvignon blanc and Merlot in New Zealand. Sourcing clean, virus-tested vines reduces the economic impact of GLRD to a value that is below any of the NPVs of disease control (Table $5)$, suggesting that vineyard managers should select virustested vines in order to maximize profits. Paying a premium of $25 \%$ on planting material derived from certified stocks is financially rewarding, although it may not initially appear to be an attractive alternative.

The estimated GLRD impact is of particular concern for the Finger Lakes wine industry given the high prevalence of viruses associated with GLRD (Fuchs et al. 2009a, Martinson et al. 2008) and the documented presence of viruliferous insect vectors and their possible role in within-vineyard transmission (Fuchs 2008, Fuchs et al. 2009b). For example, $69 \%$ of the Cabernet franc vineyards surveyed in 2006 in the Finger Lakes was GLRD-affected (Martinson et al. 2008). Application of this proportion to the Cabernet franc vineyards in the region $(\sim 55 \mathrm{ha})$ results in 38 ha of infected vineyards. Based on NPVs (Table 4), economic losses for that cultivar range from $\$ 1$ to $\$ 1.5$ million if the disease is not controlled. Evidence of high GLRD prevalence and presence of GLRaV vectors in the region is relatively recent, which might explain why some vineyard managers have underestimated GLRDrelated losses. This study, along with the recent evidence of high GLRD prevalence, provides disease impact information that vineyard managers need to take into account to implement loss-minimizing disease control measures.

Although this study sheds light on the economic impact of GLRD, the results should be interpreted with caution. For example, disease spread patterns used in the study are drawn from New Zealand (Charles et al. 2009) because no experimental data are available from the Finger Lakes. Given the low prevalence of mealybugs in the region (Fuchs et al. 2009a), the model could have overestimated the GLRD impact under the no control scenario. Future research should survey GLRD and vector prevalence over time to develop models of GLRD spread that can be used to estimate impact with more accuracy.

Earlier studies recommend controlling GLRD through roguing of symptomatic vines and their replacement with healthy ones (Freeborough and Burger 2008, Nimmo-Bell 2006, Walker et al. 2004). This study contributes to this literature by showing that roguing requires a high enough reduction in yield and/or enforcement of a price penalty on lower quality grapes to be economically justified. The $10 \%$ penalty rate reported in the survey may be too low and could underestimate the GLRD impact on wine quality. For example, Walker et al. (2004) assumed that grapes from infected vines lost $75 \%$ of their value. That is considerably higher than the penalty reported in the Finger Lakes $(10 \%$ according to the survey) and might suggest that wineries underestimate the impact of GLRD on wine quality. One study found that soluble solids were 2 Brix lower in grapes from GLRD-affected vines than from healthy vines (Martinson et al. 2008). Those grapes also had higher juice $\mathrm{pH}$ and lower titratable acidity. Further sensory analysis studies are needed to link changes in Brix and acidity to changes in wine attributes and establish quality threshold levels for the of sugar and acidity contents. Then, using wine hedonic price models, a quality penalty could be formulated in terms of ranges of sugar and acidity levels. Wineries would subsequently prevent a GLRD-related decrease in wine quality either by rejecting grapes that do not meet those thresholds or by imposing a quality penalty on those grapes and using them to produce bulk wines. This penalty can act as a price incentive for vineyard managers to control GLRD and prevent a loss in the market value of their grapes.

Over 30 winegrape cultivars are grown in the Finger Lakes. Although the analysis focuses on Cabernet franc, the results can be extended to other cultivars that are affected by GLRD in the region, such as Cabernet Sauvignon, Chardonnay, Lemberger, Merlot, Pinot noir, and Riesling (Fuchs et al. 2009a). One key reason Cabernet franc was particularly important to analyze is that it ripens later than other cultivars. This feature is crucial for cool-climate viticultural regions where early frosts make it impossible to delay harvest in GLRD-affected vines. In areas with a longer growing season and/or with early cultivars, it might be appropriate to replace the quality/penalty component of the GLRD impact with a delayed harvest component and measure the economic losses associated with the delay, if any. Finally, GLRD impact on other cultivars would be different due to differences in market prices: higher prices imply greater values of GLRD-related losses and vice versa.

Among the available disease prevention and control methods, vector control was not included in the scenarios of this study, as the efficiency of insecticides at reducing GLRD spread is still under study (Daane et al. 2008, Golino and Almeida 2008).

\section{Conclusion}

This research provides Finger Lakes vineyard managers with estimates of the economic impact of GLRD on the profitability of their businesses. Such estimates range from $\$ 25,000$ to $\$ 40,000$ per hectare for scenarios of yield reduction and quality penalty over 25 years if left uncontrolled. The results suggest that, in order to minimize potential losses due to GLRD, managers ought to prevent infection by selecting certified, virus-tested vines for replanting and by controlling the disease according to the decision matrix recommendations: that is, disease control should be based on the values of infection level, yield reduction, price penalty incurred, and vineyard age. Future research should survey the prevalence of GLRD and its vectors over time to develop models that capture the disease dynamics in the Finger Lakes. Translating our results to other grapegrowing regions with GLRD will require adjusting for differences in economic and epidemiological parameters that are unique to each region. However, independently of the region, we predict that roguing is likely to remain the best control response up to a certain level of disease prevalence, beyond which vineyard replacement may yield a higher net present value and that, most probably, no disease control will be economically justified for certain parameter values. 


\section{Literature Cited}

Charles, J., K. Froud, R. van den Brink, and D. Allan. 2009. Mealybugs and the spread of Grapevine leafroll-associated virus 3 (GLRaV-3) in a New Zealand Vineyard. Australasian Plant Pathol. 6:576-83.

Daane, K.M., M.L. Cooper, S.V. Triapitsyn, V.M. Walton, G.Y. Yokota, D.Y. Haviland, W.J. Bentley, K.E. Godfrey, and L.R. Wunderlich. 2008. Vineyard managers and researchers seek sustainable solutions for mealybugs, a changing pest complex. Calif. Agric. 62:167-176.

Freeborough, M.J., and J. Burger. 2008. Leafroll: Economic implications. [www.wynboer.co.za/recentarticles/200812-leafroll.php3] Wynboer December 2008.

Fuchs, M. 2008. Update on the Finger Lakes leafroll virus survey. In Proceedings of the $58^{\text {th }}$ Annual Finger Lakes Grape Growers Conference. H. Walter-Peterson (ed.), pp. 29-31. Cornell University Cooperative Extension, Penn Yan, NY.

Fuchs, M., P. Marsella-Herrick, G.M. Loeb, T.E. Martinson, and H.C. Hoch. 2009a. Diversity of ampeloviruses in mealybug and soft scale vectors and in grapevine hosts from leafroll-affected vineyards. Phytopathology 99:1177-1184.

Fuchs, M., T.E. Martinson, G.M. Loeb, and H.C. Hoch. 2009b. Survey for the three major leafroll disease-associated viruses in Finger Lakes vineyards in New York. Plant Dis. 93:395-401.

Ghanem-Sabanadzovic, N.A., S. Sabanadzovic, J.K. Uyemoto, D. Golino, and A. Rowhani. 2010. A putative new ampelovirus associated with grapevine leafroll disease. Arch. Virol. 155:1871-1876.

Golino, D.A., and R. Almeida. 2008. Studies needed of vectors spreading leafroll disease in California vineyards. Calif. Agric. 62:174.

Golino, D.A., E. Weber, S.T. Sim, and A. Rowhani. 2008. Leafroll disease is spreading rapidly in a Napa Valley vineyard. Calif. Agric. 62:156-160.
Goheen, A.C., and J.A. Cook. 1959. Leafroll (red-leaf or rougeau) and its effects on vine growth, fruit quality, and yields. Am. J. Enol. Vitic. 10:4:173-181.

Martelli, G.P., and E. Boudon-Padieu. 2006. Directory of infectious diseases of grapevines. International Centre for Advanced Mediterranean Agronomic Studies. Options Méditerranéennes Ser. B, Studies and Research 55:59-75.

Martin, R.R., K.C. Eastwell, A. Wagner, S. Lamprecht, and I.E. Tzanetakis. 2005. Survey for viruses of grapevine in Oregon and Washington. Plant Dis. 89:763-766.

Martinson, T.E., M. Fuchs, G. Loeb, and H.C. Hoch. 2008. Grapevine leafroll: An increasing problem in the Finger Lakes, the US and the world. Finger Lakes Vineyard Notes 6:6-11.

Nimmo-Bell. 2006. The economic effects and financial impact of GLRaV-3. 18 pp. Nimmo-Bell and Company, Wellington, NZ.

Over de Linden, A.J., and E.E. Chamberlain. 1970. Effect of grapevine leafroll virus on vine growth and fruit yield and quality. N.Z. J. Agric. Res. 13:689-698.

Tsai, C.W., A. Rowhani, D.A. Golino, K.M. Daane, and R.P.P. Almeida. 2010. Mealybug transmission of grapevine leafroll viruses: An analysis of virus-vector specificity. Phytopathology 100:830-834.

Walker, J.T.S., J.G. Charles, K.J. Froud, and P. Connolly. 2004. Leafroll virus in vineyards: Modeling the spread and economic impact. 19 pp. Report to New Zealand Winegrowers Limited, Auckland.

White, G. 2008. Cost of establishment and production of vinifera grapes in the Finger Lakes region of New York. College of Agriculture and Life Sciences, Cornell University, Ithaca, NY. 